VASCONCELLOS, M. e VIDAL, L.W.M. Mandibulectomia rostral bilateral em cão portador de plasmocitoma extramedular oral: relato de caso. PUBVET, Londrina, V. 8, N. 12, Ed. 261, Art. 1736, Junho, 2014.

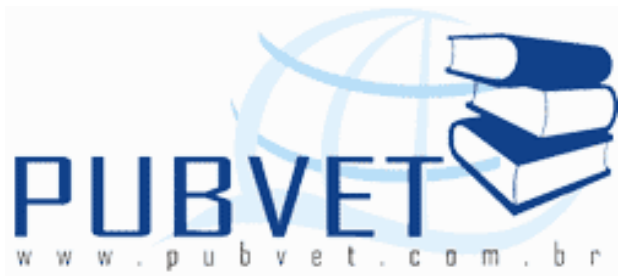

PUBVET, Publicações em Medicina Veterinária e Zootecnia.

\title{
Mandibulectomia rostral bilateral em cão portador de plasmocitoma extramedular oral: relato de caso
}

Marcel Vasconcellos ${ }^{1}$ e Leonardo Waldstein de Moura Vidal ${ }^{2}$

1 Médico Veterinário, Zootecnista, Pós-graduado em Oncologia Veterinária.

E-mail: marcelvasconcellos@yahoo.com.br

2 Médico Veterinário, Pós-graduado em Anestesiologia Veterinária.

E-mail: leo_waldstein@yahoo.com.br

\section{Resumo}

O Plasmocitoma extramedular é considerado uma neoplasia benigna. Nos cães localiza-se principalmente na pele, na cavidade oral e no trato digestivo. Seu diagnóstico conclusivo é realizado por meio de exame histopatológico. Este trabalho relata um caso de uma fêmea de 4 anos de idade, da raça Buldog Francês, que desenvolveu uma massa não ulcerada, de consistência firme, coloração rósea, medindo cerca de dois centímetros de diâmetro na região rostral da mandíbula, envolvendo o canino inferior esquerdo e incisivos adjacentes. A radiografia mandibular demonstrou lesão osteolítica em alvéolo e corpo mandibular em sua face rostral de hemi-face esquerda, além do deslocamento rostral das peças dentárias. Foi realizado tratamento cirúrgico através de mandibulectomia rostral bilateral, e em seguida, avaliado o status da margem cirúrgica, o qual não demonstrou indícios tumorais. $O$ animal foi submetido a quimioterapia adjuvante com carboplatina $300 \mathrm{mg} / \mathrm{m}^{2}$, em virtude 
VASCONCELLOS, M. e VIDAL, L.W.M. Mandibulectomia rostral bilateral em cão portador de plasmocitoma extramedular oral: relato de caso. PUBVET, Londrina, V. 8, N. 12, Ed. 261, Art. 1736, Junho, 2014.

da possibilidade aventada de invasão do canal mandibular. A paciente encontra-se saudável, desde junho/2013, não apresentando recidiva, nova tumoração, ou mesmo evidência de metástase, até a presente data.

Palavras-chave: plasmocitoma extramedular, cães, mandibulectomia.

\title{
Rostral mandibulectomy bilateral in dog carrier extramedullary plasmocytoma oral: case report
}

\begin{abstract}
The extramedullary plasmacytoma is considered a benign neoplasm. In dogs located mainly in the skin, oral cavity and digestive tract. His conclusive diagnosis is made through histopathology. This paper reports a case of a female of 4 year old, the French Bulldog breed, which has developed a nonulcerated mass of firm consistency, pinkish, measuring about two inches in diameter in the rostral region of the mandible involving the lower left canine and incisor adjacent. The radiographs showed an osteolytic lesion in mandibular alveolar and mandibular body in its rostral face of the left hemiface, beyond the rostral displacement of the teeth. Surgical treatment was performed through bilateral rostral mandibulectomy, and then assessed the status of the surgical margin, which showed no tumor indications. The animal underwent adjuvant chemotherapy with carboplatin $300 \mathrm{mg} / \mathrm{m}^{2}$, given the possibility suggested invasion of the mandibular canal. The patient is healthy, since June/2013, showing no recurrence, new tumor, or even evidence of metastasis, to date.
\end{abstract}

Keywords: extramedullary plasmacytoma, dogs, mandibulectomy.

\section{INTRODUÇÃO}

O Plasmocitoma extramedular é uma neoplasia benigna localizada, causada pela proliferação descontrolada dos plasmócitos fora da medula óssea. Estes estão presentes em qualquer tecido mole, mas principalmente na pele, 
VASCONCELLOS, M. e VIDAL, L.W.M. Mandibulectomia rostral bilateral em cão portador de plasmocitoma extramedular oral: relato de caso. PUBVET, Londrina, V. 8, N. 12, Ed. 261, Art. 1736, Junho, 2014.

na cavidade oral e no trato digestivo. Nos seres humanos, ocorrem principalmente no pulmão, oronasofaringe e seios nasais, tendo também um comportamento freqüentemente benigno. (VAIL; WITHROW, 2001)

GOLDSCHMIDT; HENDRICK em 2002, observaram maior predisposição desta neoplasia nas raças Cocker Spaniel, Poodle, Airedale Terrier, Kerry Blue Terrier, Boxer e o Scottish Terrier.

PIPPI (2008), cita que as neoplasias da cavidade oral nos cães, apresentam uma incidência ao redor de $6 \%$ do total dos tumores nesta espécie, e segundo HENRY (2001), constituem o quarto lugar mais frequente de neoplasias nos cães.

Atualmente existem muitas opções para o tratamento das neoplasias orais que incluem cirurgia, radioterapia, quimioterapia, imunoterapia com auto-vacinas, hipertermia e terapia fotodinâmica (DHALIWAL, 1998; HENRY, 2001), porém o tratamento cirúrgico, é citado por GIOSO (2003), como o de eleição e melhores resultados. PIPPI (2008), acrescenta que a radioterapia é indicada quando a resposta é previsível, quando o câncer é inoperável ou na doença residual, após a cirurgia. O autor indica a criocirurgia para lesões menores que $2 \mathrm{~cm}$ de diâmetro com mínima invasão óssea, e ressalta a ineficácia da hipertermia, devido a baixa penetração do calor no tecido ósseo, assim como da quimioterapia em cânceres com potencial metastático.

A cirurgia oncológica oral requer, incisões e dissecções amplas dos tecidos, que podem atingir $1-2 \mathrm{~cm}$ ao redor do tumor (ressecções marginais), ou mesmo no caso de ressecções amplas e radicais podem ser necessárias o uso de técnicas reconstrutivas a partir de retalhos ou enxertos. (SAN ROMAN, 1999)

PIPPI (2008) explana que o tratamento cirúrgico das neoplasias da cavidade oral baseia-se nos procedimentos de mandibulectomia e maxilectomia, sendo indicados quando ocorre invasão óssea. 
VASCONCELLOS, M. e VIDAL, L.W.M. Mandibulectomia rostral bilateral em cão portador de plasmocitoma extramedular oral: relato de caso. PUBVET, Londrina, V. 8, N. 12, Ed. 261, Art. 1736, Junho, 2014.

Em relação ao presente caso, ainda segundo este autor, a mandibulectomia rostral bilateral é indicada para lesões que cruzam a sínfise, devendo ser aplicada ao nível do primeiro ou do segundo pré-molar, podendo a língua, em alguns casos, ficar longa demais.

A aparência estética, função mastigatória e de deglutição, após procedimentos de mandibulectomia e maxilectomia nos cães, segundo LIPTAK, 2013, geralmente são muito boas, dependendo da localização do tumor e extensão da cirurgia, (fig.01,02) observações corroboradas por FOX, et al., 1997, os quais relatam um alto índice de aceitação (85\%) dos proprietários que tiveram seus animais submetidos à estes procedimentos para remoção de tumores orais.

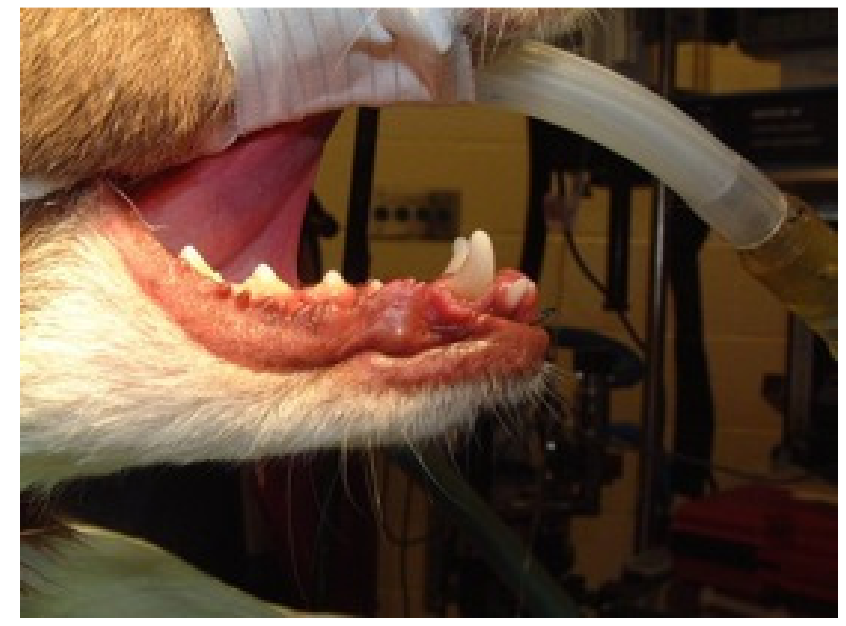

Fig.01 Fonte: Extraída de Liptak JM. Small animal surgery and surgical oncology. Disponível em

$<$ http://www.animalcancersurgeon.com/Oral Tumors.html $>$ Acesso em [30 out., 2013]. 
VASCONCELLOS, M. e VIDAL, L.W.M. Mandibulectomia rostral bilateral em cão portador de plasmocitoma extramedular oral: relato de caso. PUBVET, Londrina, V. 8, N. 12, Ed. 261, Art. 1736, Junho, 2014.

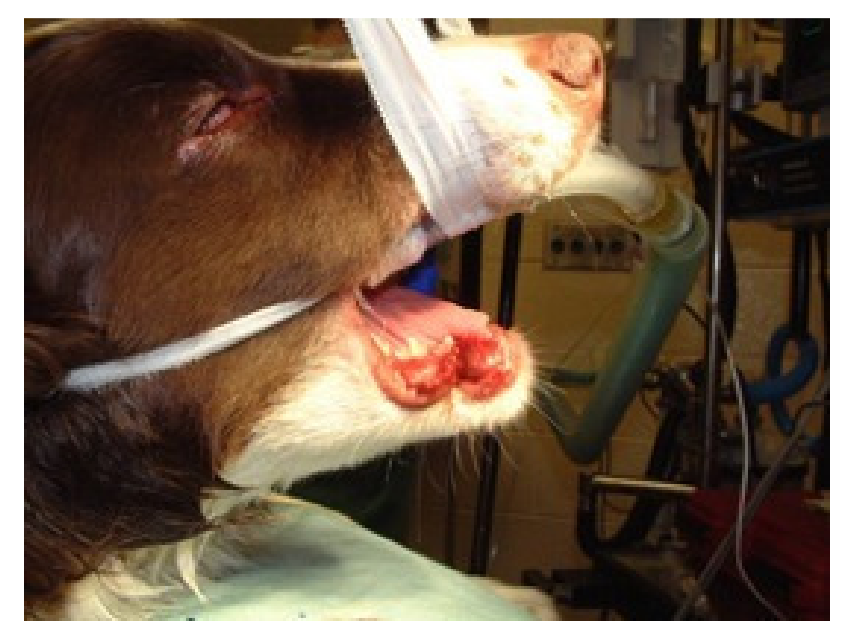

Fig.02 Fonte: Extraída de Liptak JM. Small animal surgery and surgical oncology. Disponível em

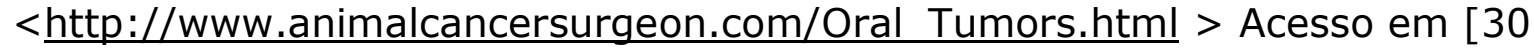
out., 2013].

Histologicamente, os plasmocitomas extramedulares cutâneos são vistos como uma proliferação bem delimitada de células redondas que se dispõe em lençóis, cordões, trabéculas ou ninhos pouco definidos e separados por pequena quantidade de tecido conjuntivo. (BAER et al. 1989; YAGER; WILCOCK, 1994) (fig 03,04)

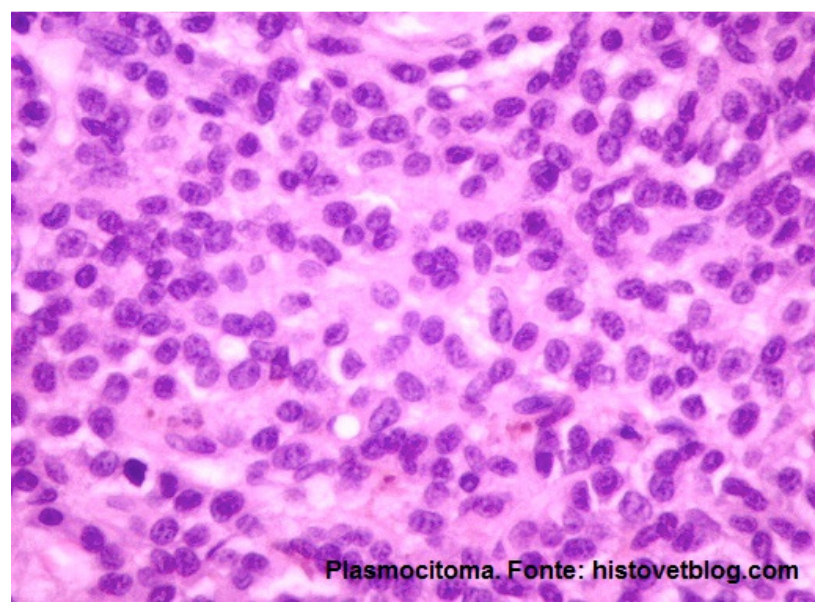

Fig.03. Fonte:histovetblog.com 


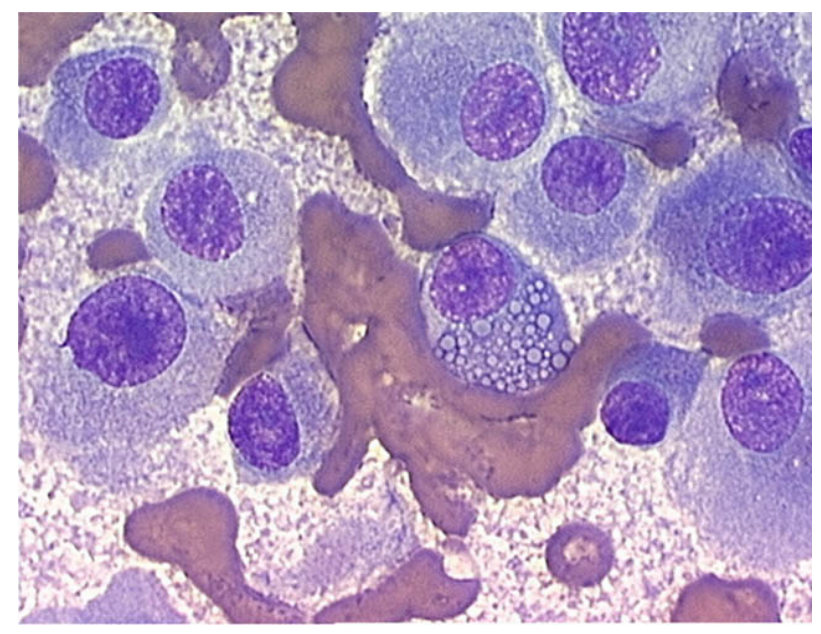

Fig.04. Fonte: histovetblog.com

$\mathrm{Na}$ histologia, os diferenciais devem incluir o histiocitoma cutâneo, o linfoma não-epidermotrópico, o mastocitoma, o tumor venéreo transmissível o melanoma maligno amelanótico (tipo epitelióide). (YAGER; WILCOCK, 1994)

Graduações histológicas para os plasmocitomas foram propostas para o cão, elas diferenciam esses tumores em grau I, Grau II e Grau III. (BAER; PATNAIK; GILBERTSON, 1989)

Em relação a formação de metástases, BERG (1998), cita que acima de $85 \%$ dos cães com tumores orais, não apresentam imagens compatíveis com metástase pulmonar no momento do diagnóstico.

Quanto ao prognóstico das neoplasias situadas na cavidade oral, NEVILLE (2004), cita que a recidiva loco-regional, após a cirurgia constitui-se no principal problema. Este termo foi questionado por SLAUGHTER (1953), que propugnava ser impossível a distinção clínica entre doença residual ou desenvolvimento de um novo tumor no mesmo sítio inicialmente tratado e dessa forma, em sua opinião, a definição de recidiva local é arbitrária.

Slaugher acrescentava que nos casos das recidivas até seis meses de pós-tratamento inicial, a manifestação clínica da doença podia ser devida a doença residual. 
VASCONCELLOS, M. e VIDAL, L.W.M. Mandibulectomia rostral bilateral em cão portador de plasmocitoma extramedular oral: relato de caso. PUBVET, Londrina, V. 8, N. 12, Ed. 261, Art. 1736, Junho, 2014.

Em um estudo que avaliou o prognóstico de 338 cães com plasmocitoma extramedular cutâneo, apenas em quatro (04) casos foram vistas metástases, e somente seis (06) cães desenvolveram recidiva em outras regiões da pele. Alguns autores acreditam que esses raros relatos de plasmocitoma extramedular cutâneo metastático, sejam na verdade casos de mieloma múltiplo com envolvimento cutâneo. Além disso, as situações interpretadas como recidivas, podem ser na verdade uma nova proliferação e não um tumor recorrente. (VAIL; WITHROW, 2001)

Considera-se que o prognóstico do plasmocitoma extramedular cutâneo em cães seja favorável, devido existirem poucos relatos de recidivas ou metástases na literatura veterinária. (YAGER; WILCOCK, 1994; VAIL; WITHROW, 2001)

\section{RELATO DE CASO}

Em consulta oncológica a um Canil domiciliado no município de Niterói Rio de Janeiro, foi atendida uma fêmea de Buldog francês, 4 anos de idade, com histórico de sialorréia, halitose, hiporexia e desenvolvimento de massa oral.

Ao exame clínico do animal, condição corporal e estado mental normais, normotermia, TPC inferior a 2 segundos, pulso forte e regular, freqüência cardíaca de 120 b.p.m (batimentos por minuto), auscultação cardíaca normal, 36 m.r.m (movimentos respiratórios por minuto), linfonodos superficiais normais, abdômen normal sem alterações.

Ao exame da cavidade bucal, observou-se que a neoformação apresentava-se assintomática, desenvolvendo-se no canino inferior esquerdo e incisivos adjacentes, não ulcerada, de consistência moderadamente firme, coloração rósea, medindo cerca de dois centímetros de diâmetro. (fig.05). 
VASCONCELLOS, M. e VIDAL, L.W.M. Mandibulectomia rostral bilateral em cão portador de plasmocitoma extramedular oral: relato de caso. PUBVET, Londrina, V. 8, N. 12, Ed. 261, Art. 1736, Junho, 2014.

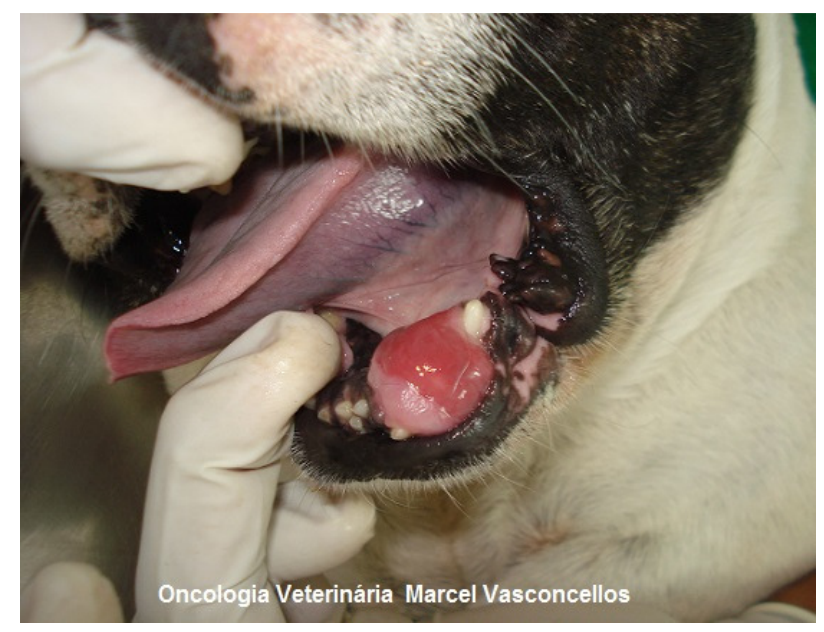

Fig.05

A radiografia mandibular demonstrou lesão osteolítica em alvéolo e corpo mandibular em sua face rostral de hemi-face esquerda, além do deslocamento rostral das peças dentárias. As demais estruturas ósseas preservadas. (fig's.06,07)

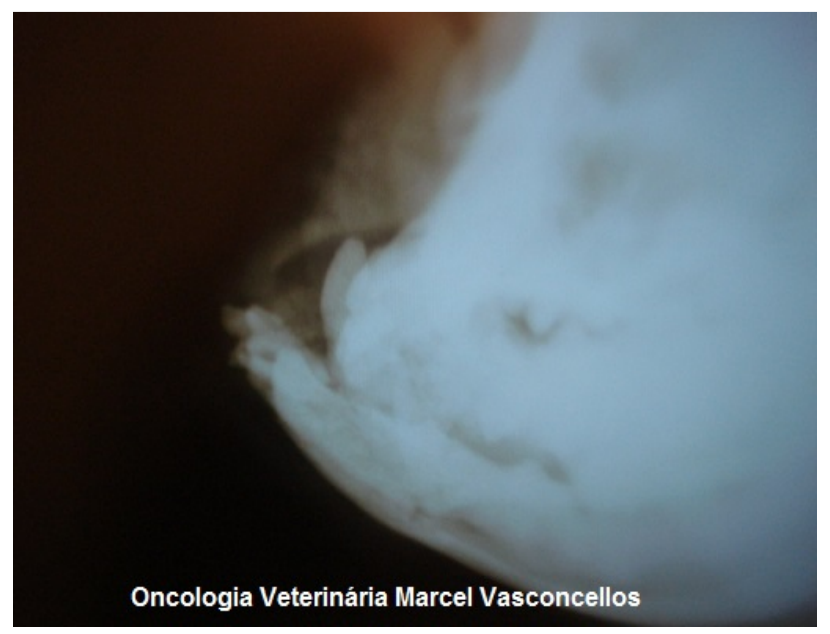

Fig. 06 


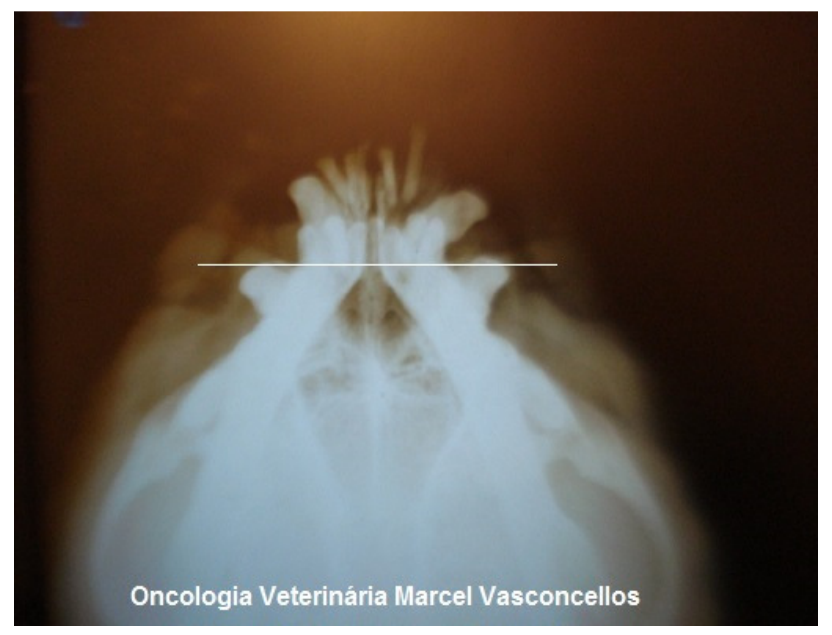

Fig.07

Com base no exame radiológico, optou-se pela biópsia excisional, dado que o conhecimento prévio do tipo histológico, não alteraria a forma de tratamento que inicialmente seria cirúrgica.

Dessa forma foram realizados exames pré-operatórios tais como hemograma completo, bioquímica da função hepática e renal, além do estudo dos campos pulmonares, através de radiografias torácicas em 03 (três) incidências (ventro-dorsal, látero-lateral esquerda e direita), todos sem alterações dignas de nota.

Após jejum alimentar de 12 horas e hídrico de 6 horas, o animal foi encaminhado ao centro cirúrgico, onde procedeu-se a aplicação de medicação pré-anestésica (MPA).

MASSONE, 1994, define a MPA, como ao ato que antecede a anestesia, preparando o animal para o sono artificial, dando-lhe a devida sedação, suprimindo-Ihe a irritabilidade, a agressividade e as reações indesejáveis causadas pelos anestésicos. 
VASCONCELLOS, M. e VIDAL, L.W.M. Mandibulectomia rostral bilateral em cão portador de plasmocitoma extramedular oral: relato de caso. PUBVET, Londrina, V. 8, N. 12, Ed. 261, Art. 1736, Junho, 2014.

Na MPA, utilizou-se tramadol $2 \mathrm{mg} / \mathrm{kg}$ de pêso corporal (p.c), associado a quetamina $0,5 \mathrm{mg} / \mathrm{kg}$ de pêso corporal (p.c), ambas por via intramuscular.

Quinze minutos após a realização da MPA, procedeu-se a rigorosa assepsia e antissepsia, sendo o paciente tricotomizado em ambos os membros anteriores para inserção de um cateter intra-venoso na veia cefálica, e administração lenta de solução de cloreto de sódio a 0,9\% e posicionamento do manguito de pressão não-invasiva.

A paciente foi induzida à anestesia com Propofol (5 mg/ $\mathrm{kg} \mathrm{p.c)} \mathrm{por} \mathrm{via}$ intravenosa lenta. Segundo MASSONE, 1994, o propofol produz um períodohábil anestésico de 10 a 15 minutos, além de discreta hipotensão e taquicardia sem alterações significativas.

Após a fase de indução, foi realizada a intubação orotraqueal com uso de pinça tira-língua, lanterna e laringoscópio além da inserção de sonda endotraqueal 7.0, conectada a um circuito semi-fechado de anestesia.

A manutenção anestésica foi feita com isoflurano em vaporizador calibrado (3 V\%).

Foi utilizado um monitor multiparamétrico para acompanhamento transcirúrgico dos seguintes parâmetros: freqüência (b.p.m) e ritmo cardíaco sinoatrial, oximetria de pulso (Po2, Pco2), frequência respiratória (m.r.m), temperatura invasiva $\left({ }^{\circ} \mathrm{C}\right)$ e pressão não-invasiva $(\mathrm{mmHg})$.

Após a antissepsia da cavidade oral, e colocação dos panos de campo, foi efetuada uma incisão na mucosa jugal em torno do lábio rostral e iniciou-se a divulsão da pele, deixando um pouco de tecido subcutâneo. Incisionou-se a mucosa do assoalho da boca entre os primeiros dentes pré-molares. Devido a presença dos ductos salivares mandibulares e sublingual, o frênulo lingual foi preservado. O músculo incisivo foi totalmente retirado, assim como parte dos músculos orbicular da boca e mentoniano. A região foi dissecada evidenciando- 
se as hemimandíbulas. Em virtude da ausência de serra oscilatória (ideal), estas foram seccionadas com o uso de mini-serra circular (fig.08).

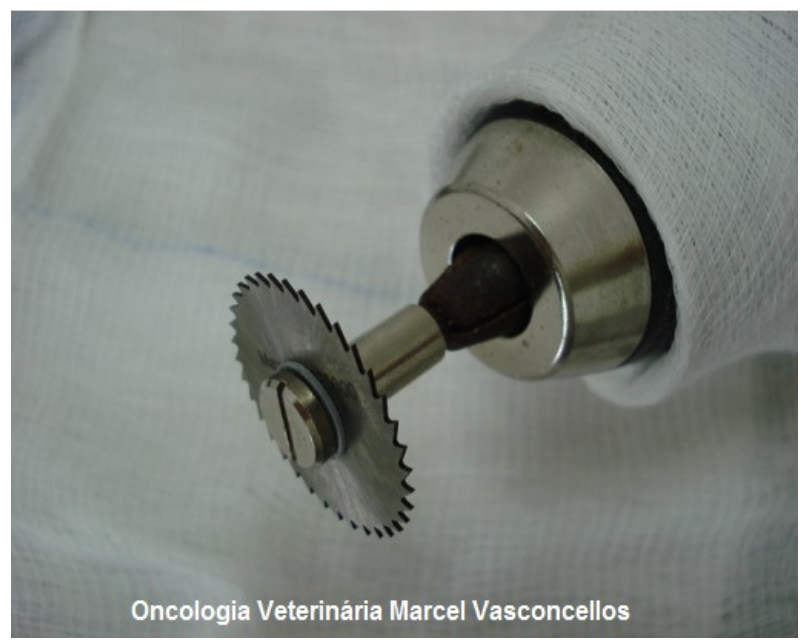

Fig.08

A hemostasia foi realizada por meio de compressão manual com gaze estéril, e do uso de pinças de Halsted. Extirpou-se parte do lábio inferior (queiloplastia em elipse), sendo sua borda suturada a mucosa gengival com fio de mononylon 3-0 através de pontos simples interrompidos com a intenção de recobrir as hemimandíbulas. Estas foram arredondadas com uso da mini-serra circular, de modo a não causar lesão na mucosa labial e assim diminuir a tensão. A mucosa vestibular foi igualmente suturada a mucosa labial, com fio de mononylon 2-0. Ao término do procedimento (fig.09), todo o local foi higienizado com solução aquosa de PVPI a 0,1\%.

Durante o período trans-cirúrgico, não se observou nenhuma alteração digna de nota. A paciente foi extubada e verificou-se parâmetros fisiológicos e presença de reflexos. Em seguida, a mesma foi colocada em colchonete térmico para um melhor restabelecimento. 
VASCONCELLOS, M. e VIDAL, L.W.M. Mandibulectomia rostral bilateral em cão portador de plasmocitoma extramedular oral: relato de caso. PUBVET, Londrina, V. 8, N. 12, Ed. 261, Art. 1736, Junho, 2014.

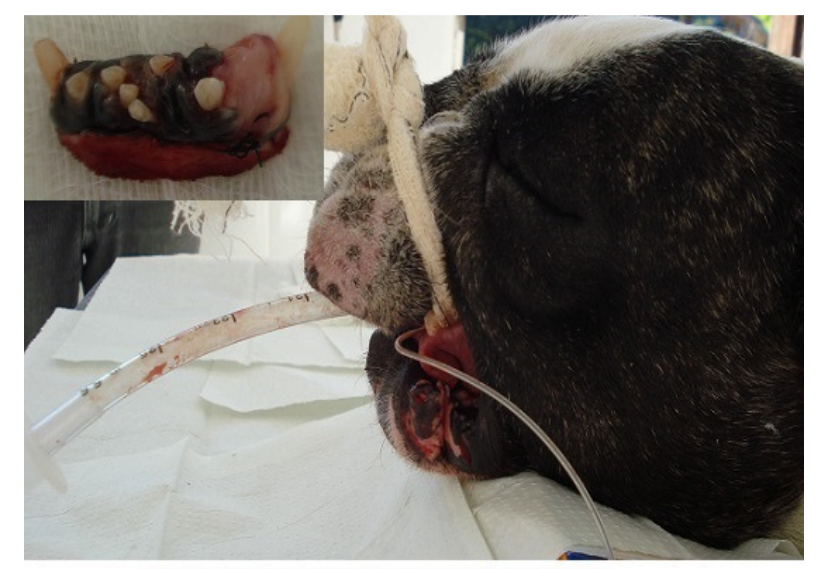

Oncologia Veterinária Marcel Vasconcellos

Mandibulectomia rostral bilateral

Fig.09

A peça cirúrgica obtida por biópsia excisional foi acondicionada em frasco contendo formaldeído à $10 \%$ e encaminhada para exame histopatológico (fig.10).

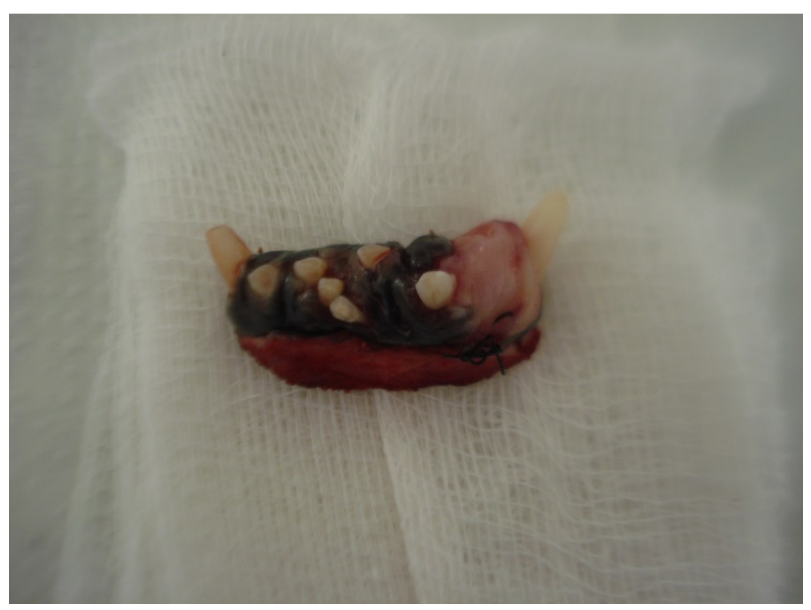

Fig.10.

O diagnóstico, confirmado através de exame anátomo-patológico, revelou; Macroscopia: fragmento de mandíbula irregular, pardo-claro de consistência elástica. Microscopia: Neoplasia constituída por proliferação de plasmócitos, por vezes, com pleomorfismo nuclear e binucleação. Ausência de 
VASCONCELLOS, M. e VIDAL, L.W.M. Mandibulectomia rostral bilateral em cão portador de plasmocitoma extramedular oral: relato de caso. PUBVET, Londrina, V. 8, N. 12, Ed. 261, Art. 1736, Junho, 2014.

pigmento e de granulação citoplasmática. Conclusão: Plasmocitoma (ausência de malignidade). Margens livres (não especificadas).

Prescreveu-se tramadol $2 \mathrm{mg} / \mathrm{Kg} / \mathrm{QID} / \mathrm{VO}$ por 7 dias, meloxican 0,2 $\mathrm{mg} / \mathrm{Kg} / \mathrm{SID} / \mathrm{VO}$ por 5 dias e cefalexina $20 \mathrm{mg} / \mathrm{Kg} / \mathrm{BID} / \mathrm{VO}$ por 7 dias, além do uso de colar elisabetano, higienização oral com gluconato de clorexidina a 0,12\% QID/ 15 dias, e dieta pastosa por 15 dias (a/d TM Canine / Feline Critical Care da Hills Pet Nutricion $®)$.

Após 28 dias, iniciou-se protocolo monoquimioterápico através do uso de Carboplatina $300 \mathrm{mg} / \mathrm{m}^{2}, 21 \times 21$ dias, total de 04 sessões, com acompanhamento hematológico e bioquímico das funções hepática e renal, antes de cada sessão.

O animal não apresentou neste período, qualquer intercorrência.

\section{RESULTADOS E DISCUSSÃO}

GIOSO, 2003, relata que os cães braquicefálicos (ex: Buldog Francês), são portadores de um prognatismo relativo, pois embora o tamanho de sua mandíbula e maxila seja aceito e desejáveis para a raça, existe uma protrusão "aparente" da mandíbula. O que se encontra, na verdade, é um encurtamento da maxila e não uma mandíbula alongada. É errado referir-se a estas raças como sendo prognatas normais.

Dessa forma, a redução em torno de $20 \%$ do comprimento da mandíbula, apenas reduziu esta "aparente" protusão, não afetando o aspecto estético do animal, o que foi bem aceito pelo proprietário.

Em relação ao aspecto funcional, não houve perda da função mastigatória normal. Observação justificada, pelo fato dos cães realizarem a preensão dos alimentos utilizando seus membros anteriores para segurar os 
alimentos, ao que este é passado ao interior da boca principalmente pelo movimento da cabeça e mandíbula, os quais não foram afetados.

A mastigação nos carnívoros, ocorre através dos movimentos mandibulares que atuam principalmente no plano vertical e produzem uma ação de cisalhamento. A trituração pelos dentes molares é realizada imperfeitamente, sendo o alimento deglutido quase diretamente, sem que haja uma completa mastigação. (JAVAUTO, 2013)

Do ponto de vista oncológico, a constatação de margens livres da peça submetida a histopatologia, sem a especificação desta margem, não foi considerada segura em relação a uma provável disseminação neoplásica através do canal mandibular, o que justificou, a necessidade de adoção da quimioterapia adjuvante, como forma de controle sistêmico da doença.

Atualmente o animal encontra-se em avaliação de seguimento, sendo solicitado ao proprietário, seu retorno a cada 03 meses. Ressalta-se neste caso, o bom resultado estético e funcional obtidos. (fig.11)

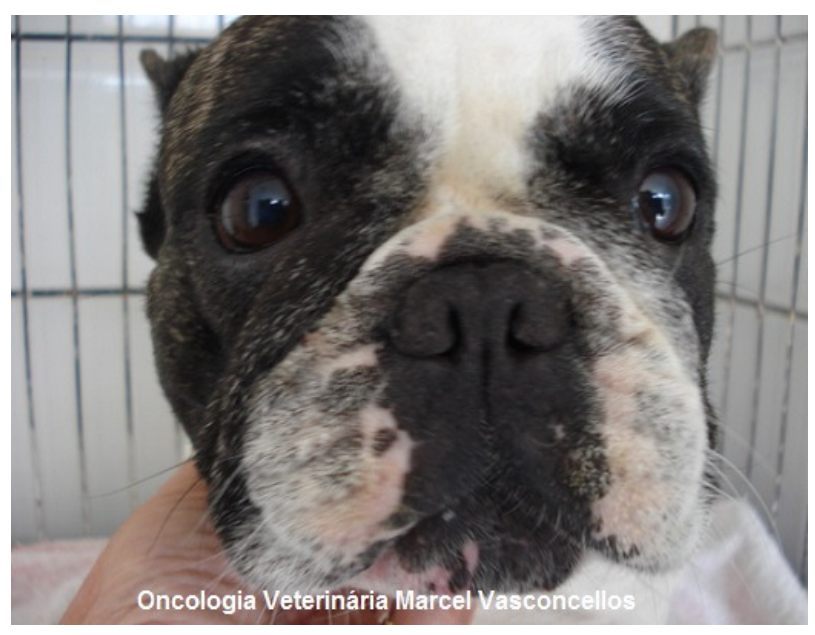

Fig. 11 
VASCONCELLOS, M. e VIDAL, L.W.M. Mandibulectomia rostral bilateral em cão portador de plasmocitoma extramedular oral: relato de caso. PUBVET, Londrina, V. 8, N. 12, Ed. 261, Art. 1736, Junho, 2014.

\section{CONCLUSÃO}

Em relação ao tratamento inicial do câncer, a cirurgia oncológica é considerada como a melhor e mais preciosa oportunidade de cura da doença, e dessa forma, muitas vezes procedimentos radicais e mutilantes tornam-se necessários, objetivando preservar a vida do paciente.

Considerações estéticas e funcionais são igualmente importantes e devem ser consideradas durante o ato cirúrgico.

O tratamento do câncer, requer conhecimento do comportamento biológico tumoral e planejamento terapêutico adequado as condições econômicas e técnicas de cada caso.

A conscientização dos proprietários em adaptarem-se a nova condição de vida de seus animais, assim como a cooperação e entrosamento da equipe multidisciplinar envolvida, se traduzem numa melhor qualidade de vida para o paciente oncológico.

\section{REFERÊNCIAS BIBLIOGRÁFICAS}

Baer KE, Patnaik AK, Gilbertson SR, et al. Cutaneous plasmocytomas in dogs: a morphologic and immunohistochemical study. Veterinary Pathology, v.26, n. 3, p.216-21, 1989.

Berg J. Principles of oncologic orofacial surgery. Clin Tech Sm Anim. Pract, 13(1), 38-41, 1998.

Dhaliwal RS. Oral tumors in dogs and cats. Part II. Prognosis and treatment. The Compendium. v.20, n.10, p.1109-119, 1998.

Fox LE, Geoghegan SL; Davis LH, et al. Owner satisfaction with partial mandibulectomy or maxilectomy for treatment of oral tumors in 27 dogs JAAHA. 33:25-31, 1997.

Gioso MA. Odontologia veterinária para o clínico de pequenos animais apud Hoffmann-Appollo F. Estudo comparativo da forma do crânio de cães braquicefálicos e mesaticefálicos por meio de técnicas de morfometria geométrica em três dimensões. [Tese de Mestrado]. Faculdade de Medicina Veterinária e Zootecnia. Universidade de São Paulo (USP-SP); 2009.

Goldschimidt $\mathrm{MH}$, Hendrick MJ. Tumors of the skin and soft tissues. In: Meuten DJ. Tumors in domestic animals. 4a ed. Ames: Iowa State, p.44-117, 2002.

Henry CJ. Tumores malignos de la cavidad oral en perros y gatos. Waltham Focus. v.11, n.4, 2001. 
Javauto JA, et al. Fisiologia dos animais domésticos. Disponível em URL: < http://www.medvet.hpg.ig.com.br/fiosiologistdigest01.htm > [ 2013 out 30]

Liptak JM. Small animal surgery and surgical oncology. Disponível em URL: < http://www.animalcancersurgeon.com/Oral Tumors.html >[ 2013 out 30]

Massone F. Anestesiologia veterinária. 2a Ed. Rio de Janeiro. Guanabara Koogan; p.19/68, 1994.

Neville BW, Damm DD, Allen CM. Bouquot JE. Patologia oral e maxilofacial. 2a ed. Rio de Janeiro: Guanabara, p.551-55, 2004.

Pippi NL. Neoplasias da cavidade oral. In: Oncologia em cães e gatos. Daleck CR, De Nardi AB, Rodaski S. São Paulo: Roca, p.313-16, 2008.

San Roman FS. Atlas de odontologia de pequenos dos animais apud Riva FPL. Anatomia dos tecidos moles e glândulas salivares do sistema estognomático de cães e gatos; enfoque anátomo-cirúrgico. [Tese de Mestrado]. Faculdade de Medicina Veterinária e Zootecnia. Universidade de São Paulo (USP-SP); 2005.

Slaughter DP, Southwick HW, Smejkal W. Field cancerization in oral stratified squamous epithelium apud Chedid HM, et al. O seguimento nas recidivas loco-regionais no câncer de bôca e orofaringe. Arq. Int. Otorrinolaringol., São Paulo, v.13, n.1, p.69-77, 2009.

Vail DM, Withrow SJ. Tumors of the skin and subcutaneous tissues. In: Withrow SJ; Macewen EG. Small animal clinical oncology. 3a ed. Philadephia: Saunders Company, p.233-260, 2001.

Yager JA, Wilcock BP. Color atlas and text of surgical pathology of the dog and cat: dermatopathology and skin tumors. $2^{\mathrm{a}}$ ed. Toronto: Wolfe, p.320, 1994. 